\title{
Empleo digno para trabajadores migrantes en todo momento: implementar el modelo de cero cuotas y pago por parte del empleador para la contratación de trabajadores migrantes
}

Decent work for migrant workers at all times: implement zero fees and employer pays model for recruitment of migrant workers

Una declaración del Foro Migratorio en Asia (MFA, por sus siglas en inglés), el Centro Interregional para Refugiados y Migrantes (CCRM, por sus siglas en inglés), el Consejo Sindical Regional del Asia Meridional (SARTUC, por sus siglas en inglés), la Asociación de Organizaciones no Gubernamentales de las Islas del Pacífico (PIANGO, por sus siglas en inglés), la Región del Pacífico y el Centro de Solidaridad.

ISSN IMPRESO 1870-7599 | ISSN RED CÓMPUTO 2448-7783 | 179-183

Mientras la pandemia de covid-19 afecta notablemente la vida de cada individuo, la severidad de su impacto recae en gran medida en el sector más débil de nuestra sociedad. Las amplias repercusiones de la pandemia amenazan no sólo a la salud, el bienestar y el sustento del ser humano, sino a la estabilidad económica y política de un país. Esto en conjunto exacerba la lucha de los grupos vulnerables, incluyendo a los trabajadores migrantes - un número considerable ha dado positivo a la covid-19_; al personal de la salud, puesto que se ubica en la primera línea atendiendo a pacientes enfermos; a migrantes que viven en dormitorios concurridos e insalubres y que han sido de igual modo infectados; a trabajadoras domésticas migrantes, quienes laboran jornadas más largas y están expuestas a la violencia en su área de trabajo sin la posibilidad de buscar ayuda debido a las medidas de cuarentena puestas en marcha. 
En el actual sistema económico mundial, los trabajadores migrantes pagan exorbitantes cuotas de contratación para asegurar trabajos poco remunerados; como resultado, generalmente permanecen endeudados hasta por uno o dos años antes de que puedan ganar un salario digno que les permita mantenerse a sí mismos y a sus familias. La reciente crisis de coronavirus de manera abrupta ha puesto fin al despliegue y empleo de miles de trabajadores migrantes alrededor del mundo, muchos de ellos tienen deudas con agentes, subagentes, algún miembro de la familia o pequeñas empresas prestamistas en su lugar de origen.

Si hay algo que se puede aprender de esta crisis es que es necesario suprimir radicalmente la situación presente y avanzar hacia un modelo de pago del empleador respecto a la contratación, en el sentido de que ningún trabajador debería endeudarse para asegurar un empleo.

Los Objetivos de Desarrollo Sostenible 2030 (ODS) reconocen la contribución positiva de los migrantes en el crecimiento inclusivo y el desarrollo sustentable. El objetivo ocho, centrado en el trabajo digno, pide además la protección de los derechos laborales, así como la promoción de ambientes seguros para todos, toma en cuenta a migrantes, en particular a las mujeres y a los que tienen un empleo precario.

El Pacto Mundial para la Migración (GCM, por sus siglas en inglés), adoptado por los gobiernos en 2018, exhorta específicamente a los Estados a facilitar una contratación justa y ética, asimismo a salvaguardar condiciones que garanticen el trabajo digno. De manera complementaria, el GCM instó a los gobiernos a prohibir el cobro de cuotas de contratación por parte de los reclutadores y empleadores, o bien otro cargo relacionado a los trabajadores migrantes con el propósito de prevenir la servidumbre por deudas, la explotación y el trabajo forzoso; incluido el establecimiento de mecanismos obligatorios y aplicables para la efectiva regulación y monitoreo del sector de contratación.

A escala global, agencias de las Naciones Unidas (UN, por sus siglas en inglés) han solicitado también a los gobiernos y a todos los interesados que aborden las problemáticas en torno a la contratación de trabajadores migrantes y a la prohibición del cobro de cuotas de contratación. Los principios generales y las pautas operativas de la Organización Internacional del Trabajo (OIT) para la contratación justa establecen que las cuotas o cualquier otra tarifa vinculada no deben ser cobradas a los trabajadores por ningún empleador, subsidiarios, reclutadores ni terceros que proporcionen servicios relacionados. La Organización Internacional para las Migraciones (OIM) ha erigido el Sistema Internacional 
de Integridad en el Reclutamiento (IRIS, por sus siglas en inglés), cuya norma prohíbe el cobro de cuotas de contratación u otro tipo de cobro asociado con aquellos que buscan trabajo.

Los Procesos Consultivos Regionales (RCP, por sus siglas en inglés) han admitido que el conseguir trabajos dignos para los migrantes los obliga a tratar asuntos relativos a este tópico. La declaración ministerial del Proceso Colombo de 2016 recomienda a los Estados miembro trabajar hacia la transformación de la industria de contratación, con el propósito de asegurar que el reclutamiento de trabajadores migrantes de países miembros del Proceso Colombo sea libre de costo. El Diálogo de Abu Dhabi de 2017, en su cuarta consulta ministerial, declaró que los Estados miembro continuarán dando prioridad a la cooperación regional, orientada a promover prácticas de contratación laborales justas, legales y transparentes.

Mientras los países siguen implementando medidas de cuarentena y confinamiento, muchas industrias en países de destino permanecen cerradas, esto ha provocado una pérdida de millones de empleos que afecta a trabajadores migrantes. Algunos han sido obligados a marcharse sin goce de sueldo, otros lidian con reducciones de pago, un sector más se encuentra desempleado y sin ningún tipo de ingreso.

La rápida evolución de este hecho en países de destino ha interrumpido el despliegue tanto de los nuevos trabajadores migrantes como de los que regresan, de manera que varios permanecen en el «limbo», con la incertidumbre incluso de saber si todavía conservan sus empleos. Paralelamente, los trabajadores migrantes que se encuentran fuera de casa tampoco están seguros de su situación laboral, desconocen si ya es conveniente volver a sus empleos en el extranjero.

Más allá de la preocupación referente a las condiciones de los trabajadores migrantes en los países de destino y los que continúan varados en los países de origen, se pasa por alto un aspecto, independientemente de la vulnerabilidad de los migrantes en el contexto actual, ya que muchos de ellos deben saldar sus deudas adquiridas con el empleador o con terceros, sin importar su condición laboral. Endeudados y sin poder trabajar para ganarse la vida, los trabajadores migrantes enfrentan una realidad insostenible. A fin de liquidar sus deudas, y en un acto de desesperación, habrá quienes acepten trabajar en condiciones de explotación. Mientras que otros podrían oponerse a la repatriación, después de que las restricciones de viaje se hayan levantado, y seguir trabajando como indocumentados para tener la capacidad de pagar sus deudas y proveer a sus familias. 


\section{Proporcionar trabajo digno para los migrantes y mantener el modelo de pago del empleador}

Con motivo del primero de mayo de 2020, reiteramos los llamados a un trabajo digno y a la contratación justa de los ODS de 2030, el Pacto Mundial para la Migración, la Agenda de Contratación Justa de la OIT, la norma IRIS de la OIM, el Proceso de Colombo y el Diálogo de Abu Dhabi. Exhortamos a los gobiernos a garantizar que ningún trabajador pague tarifas de contratación y a la vez asegure un trabajo digno. Asimismo, recomendamos que se tomen las siguientes acciones:

1. Instamos a los gobiernos a revisar y enmendar las políticas y los procedimientos existentes sobre la contratación, con el objetivo de considerar situaciones de crisis como la actual pandemia de covid-19.

2. Los gobiernos deben asegurarse de que en este momento de crisis las agencias privadas de contratación (abarca a los países de origen y de destino) estén obligadas a brindar apoyo a sus trabajadores, especialmente a aquellos que se encuentran en los primeros seis meses de contrato.

3. Las asociaciones y alianzas privadas de contratación deben crear un fondo de emergencia para que sus integrantes puedan apoyar a los trabajadores en tiempos de crisis.

4. Los gobiernos deben exigir a las agencias privadas de contratación que presenten un informe sobre la situación de los trabajadores migrantes que han empleado.

5. Los gobiernos deben demandar a las agencias privadas de contratación que muestren una lista de los migrantes a quienes han cobrado cuotas y que aún esperan su despliegue.

6. Los trabajadores que pagaron cuotas de contratación, pero no fueron empleados debido a la pandemia de covid-19, deben ser reembolsados por parte de las agencias privadas de contratación para solventar sus gastos.

7. Las agencias privadas de contratación deben ayudar a los gobiernos en la repatriación de trabajadores que perdieron sus empleos o que actualmente están varados en los países de destino.

8. Las agencias privadas de contratación deben garantizar que los trabajadores infectados por covid-19, puedan buscar atención médica en los países de destino o de origen. 
9. Las agencias privadas de contratación deben apoyar en la repatriación de los trabajadores varados en los países de destino que todavía continúan bajo contrato del reclutador.

10. Las asociaciones de agencias de contratación deben asegurarse de que sus miembros cumplan con el programa de contratación justa de la OIT y la Norma OIM, IRIS.

11. Los gobiernos deben establecer bases de datos con los contactos de trabajadores migrantes que hayan perdido su empleo y regresado a sus hogares, ello para que una vez que vuelva a estar disponible su trabajo reanuden las actividades, inclusive, ya con una experiencia de contratación más ágil y directa, no tengan necesidad de acudir a las agencias de reclutamiento y otras formalidades. 